\title{
Complementing Education via Virtual Labs: Implementation and Deployment of Remote Laboratories and Usage Analysis in South Indian Villages
}

\author{
http://dx.doi.org/10.3991/ijoe.v12i03.5391
}

\author{
S. Diwakar, D. Kumar, R. Radhamani, H. Sasidharakurup, N. Nizar, \\ K. Achuthan, P. Nedungadi, R. Raman, and B. Nair \\ Amrita University, Amritapuri, Kerala, India
}

\begin{abstract}
ICT-enabled virtual and remote labs have become a platform augmenting user engagement in blended education scenarios enhancing University education in rural India. A novel trend is the use of remote laboratories as learning and teaching tools in classrooms and elsewhere. This paper reports case studies based on our deployment of 20 web-based virtual labs with more than $170+$ online experiments in Biotechnology and Biomedical engineering discipline with content for undergraduate and postgraduate education. Via hands-on workshops and direct feedback using questionnaires, we studied the role of remote lab experiments as learning and teaching tools. Although less reliable than direct feedback, we also included online feedback to perceive blended and remote learning styles among various users. Student and teacher user groups suggested significant usage adaptability of experimental process and indicated usage of remote labs as supplementary tools for complementing laboratory education. Usage analysis implicated the role of online labs as interactive textbooks augmenting student interaction and positive correlates to learning.
\end{abstract}

Index Terms-Virtual lab; Blended learning; Direct feedback; Neurophysiology; Biophysics; Bio-inspired robotics; ICT; Remote labs; Hands-on workshops.

\section{INTRODUCTION}

Laboratory-based courses have a vital role in both engineering and scientific education [1]. Financial cost for developing physical experimentation setups, difficulties in maintaining the lab equipment and the lack of trained teachers were the main drawbacks for many institutions in developing nations like India [2], [3] to setup advanced student laboratories. Recent developments in Information and Communication technologies (ICT) have shown novel perspectives of employing animations, simulations and internet enabled remote laboratories within curriculum [4]. Remote labs have also become popular amongst the teachers and students worldwide leading to many definitions in literature [5]. In context, a remote laboratory is a hybrid approach that provides emulated or internet-based access to the experimental setup [6]. Remote experiments also allow users to access real scientific data, controlling the experiment from a distant location [7]. This has been reported to kindle curiosity among student users by providing an opportunity to learn concepts and practice scientific aspects through remote experimentation [8]. Content-rich remote labs have enabled an active role in personalizing learning behavior among students, thereby creating a novel learning pedagogy with minimum forced involvement during classroom lectures [9]. Studies also have reported extended usage of ICT for education had aided modeling a collaborative teaching scenario reducing some of the problems faced in a traditional classroom environment [10].

Remote labs, where the users interact with the remotely located hardware set-up, have been implemented by various universities for fulfilling the educational objectives of a traditional classroom [11]. Some virtual labs have been effectively implemented in electrical engineering and other disciplines of science [12]. Studies have also reported on various ways of remotely controlling, accessing data acquisition and operating equipment for experiments mainly in mechanical engineering[13]. MIT iLabs, integrated real hardware electrical engineering remote labs and shared it across many universities and provided an opportunity to the students for conducting experiments from the comfort of any internet-accessible browser [14]. University of Technology Sydney's remote laboratory also implemented physical equipment that was cameraenabled and connected to an internet facility [15]. Virtual Instrument Systems in Reality, a project by Blekinge Institute of Technology together with National Instruments in USA and Axiom EduTech in Sweden implemented remote panels for electronics labs; Library of Laboratory (LILA) also implemented remote laboratory setup to favor engineering education[16]. European Schoolnet, PROLEARN and LabShare Sahara are good examples of providers of collaborative distant laboratories. Such implementations were made accessible anytime via the internet.

Even though, remote labs are showcased as a new venture in enhancing educational needs, only few studies have been reported determining the role of design of online experiments, complexity and challenges faced for expedient implementations to fulfill the prerequisites of the user community[17]. For optimal student coverage, the module design in remote labs should match with the conventional laboratory syllabi while the web implementation phase could ensure addressing common issues such as scalability, usability and security systems within the hardware 
framework[18]. Studies have also indicated the efficiency of remote labs largely relied on internet bandwidth and network connectivity [19]. Issues such as timemanagement, difficulty in generating average connectivity speed for the clients and the deliverability efficiency have posed a challenge to deliver quality education in most developing nations, especially in India[10].

In this paper, we present design and implementation of online and remote laboratories for an Indian laboratory setting. The objective was to make available laboratory education ubiquitously to geographically and financiallychallenged institutions and to augment equipment access for reusing and repurposing remote education. Pedagogical analyses were also carried out to analyze the role of remote labs in enhancing laboratory education in different universities.

\section{A. Virtual lab and remote labs as online education platform}

There have been extensive evidence on the usage of web-based learning platforms in classrooms over the last few decade [201. Such technologies have shown to provide new innovations as effective educational tools for imparting exciting opportunities to improve the quality of teaching and science literacy[9]. VALUE labs have been implemented as part of ICT initiative and its role has been tested between students and teachers of various Indian universities[21]. Studies have shown that virtual labs improved teaching and learning experiences via improved user interaction and played a pivotal role in reducing the problems faced by a traditional laboratory education especially in remote areas $[221$. In a study conducted amongst university teachers from different institutes, it was shown that virtual laboratories were used by the teachers as a teaching element in their daily classroom scenario that helped them to monitor the performance of students $[22\rceil$. A previous paper had reported usage of virtual labs as an education platform helped enhance the active learning process of the students [23].

As part of a project, we developed such ICT-enabled labs freely available via http://vlab.amrita.edu [24]. In the context of learning, animations were graphics-based sequences to virtualize wet laboratory methods with a close collocation to observing a real lab scenario [10], [25]. Simulations used mathematical models with a series of biophysical approximations facilitating user interaction [26] and mathematical reconstructions of real-life datasets. Remote labs required intense engineering techniques to provide online users access to lab equipment (Figure 1.A). The experiments under 'remote panel'[24] were designed to provide remote access to a single user at a time. Remote experimentation techniques have aided to overcome some laboratory teaching issues faced by student and teacher communities [27]. Keeping internet connectivity and access to pre-installed plugins in consideration, a user-friendly interface (Figure 1B) was designed for the quick access of the equipment. Live video streaming was included to provide a perceived feel of equipment usage and operation of the physical laboratory.

To maximize productivity and eliminate resource conflicts, a scheduling system was implemented. This slot booking system allowed users to reserve practice-directed time slots [28]. With current design, the scheduler allowed only one user to access a remote lab experiment. Video streaming was enabled via an ordinary webcam allowing to monitor remote equipment. We observed that allowing users to monitor remote equipment enhanced student engagement with the activity (data not shown). A streaming media server facilitated multiple video streams. In experiments where live action was not equipment movement, video frame rate was reduced [10] to save bandwidth. For remote experiments, video streaming required considerably greater network speeds than textual content. In some experiments, like with RT light microscope [24], live video frame rate was set higher, requiring manual settings of higher data buffer length for the media encoders. With our focus on villages in India, bandwidth and streaming issues were common when more than 10 media streams operated concurrently. At the server end, a high bandwidth connection was required for regular usage.

Access to remote experiments was via user authentication. User was required to sign in with any registered id or with a Google id or an open-id to get access to the remote lab set-up. Kerberos-based single sign on was employed to permit user access to all devices or virtual labs without being prompted to log on individually [29].

\section{B. Virtual Neurophysiology Laboratory}

Before developing other 22 labs, as a pilot phase, we developed a hybrid Virtual Neurophysiology Lab with simulation, interactive animations and remotely controlled experiments. Neurophysiology is the study of nervous system function and relates information sciences with neurobiology, psychology, neurology, clinical neurophysiology, electrophysiology, biophysical neurophysiology, ethology, neuroanatomy, cognitive science and other brain sciences. Besides the use of costly reagents and live tissue or animals, training students in neurophysiology demands extensive knowledge and trained lab instructors.

A.

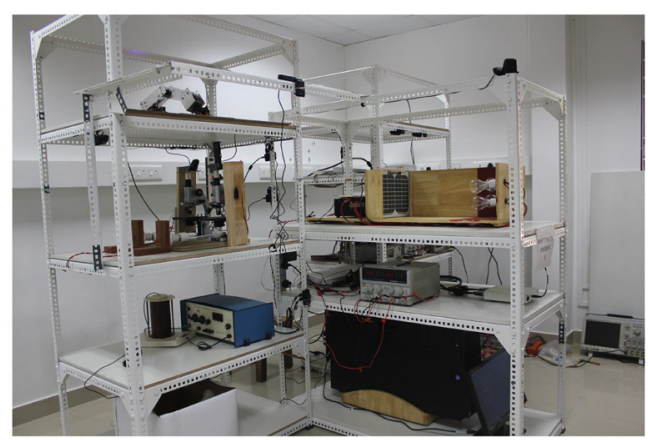

B.

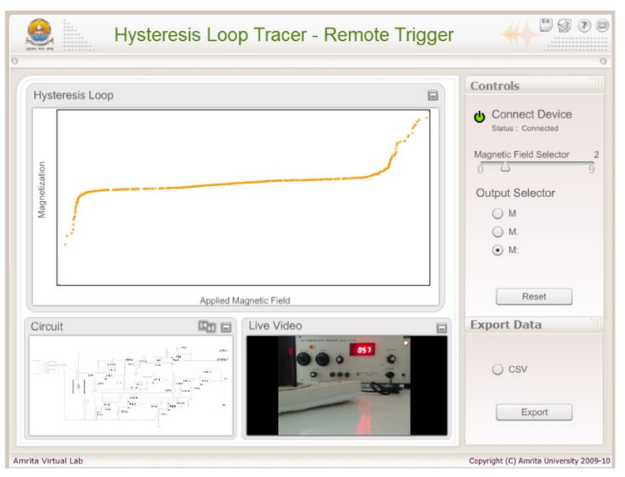

Figure 1.

A. Remote experimental setup for Virtual Labs. B. Graphical User Interface of a remote controlled experiment 
Moreover, demonstrating real lab techniquesto postgraduate students in Biotechnology needed approximately 6-10 hours to complete one session of training and about 2-3 weeks to train one student, leaving electrophysiology unsuitable as a lab course in several institutions in emerging economies. As a complementary learning tool, virtual neurophysiology laboratory was designed to provide an opportunity for teachers and students to substitute neurophysiology demo course with virtualized techniques and protocols of a real laboratory. In neurophysiology remote labs, analogs of neural models have been designed to understand real-time processing of information flow in the form of ionic current. Analogs of neuron and network circuit was designed using transistors, resistors, capacitors and an injected current mimicking biological function. Ion channels were modeled using a diode (Available for free access at http://vlab.amrita.edu/?sub=3\&brch=43).

\section{Biophysics Virtual Labs}

We made 8 online experiments on biophysics Biophysics allowing student users to remotely trigger analogs mimicking cell and tissue behavior. This lab provided an interactive experience on learning biophysical concepts such as membrane conductivity, electrical activity and membrane transport and some basis on biophysical techniques such as light microscopy (see Figure 2, Figure 3A and Figure 3B and http://vlab.amrita.edu/?sub $=3 \&$ brch=258).

\section{Bio-inspired robotics virtual labs}

The robotics and control has advanced from engineering to bio-inspired designs in many laboratory courses. We developed remotely controlled bio-inspired robotic laboratory (Figure 4) that aims to introduce bio-robotics and neural control techniques. The main focus of this lab is to provide practical skills in using simple electronics to reinforce application of bio-inspired ideas (http://vlab.amrita.edu/?sub=3\&brch=257) .

Each experiment (see Table I) in the lab included a theory tab that described the principle behind each experiment. The procedure part provides instructions on working of each experiment and experimental parameters. Users were also informed about parameter changes in the experiment for virtual experimental lab procedure. A quiz tab, self-evaluation and an assignment tab were also provided as additional material to allow users to self-test their theoretical and practical skills with the remote labs. Online feedback was used to estimate involvement of users in each experiment.

\section{E. Virtual and Remote Lab Architecture}

Using VLCAP platform[30] and DAQ-based (see Figure 5) control, remote equipment was controlled via simple push instructions passed through XML configuration file. Controlled access allowed some degree of feel of a traditional laboratory and to ensure reliability, scalability and usability for the user-end. It also has centralized virtual lab repository that include links to particular experiments, usage information, usage logs and assessment results and related assignments for learners.

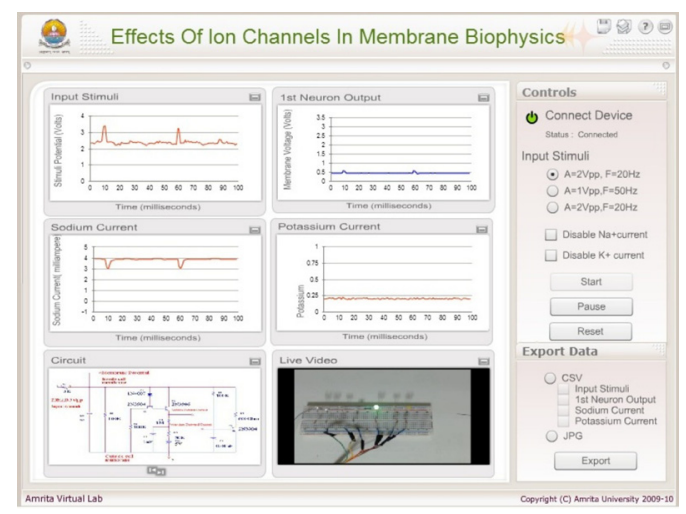

Figure 2. Study of RC Properties of Cell Membrane via Remote Labs

A.

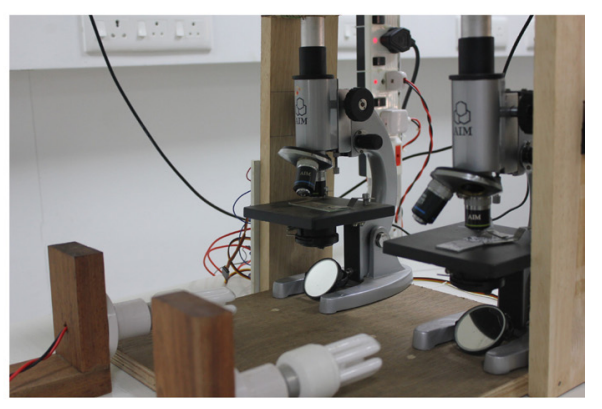

B.

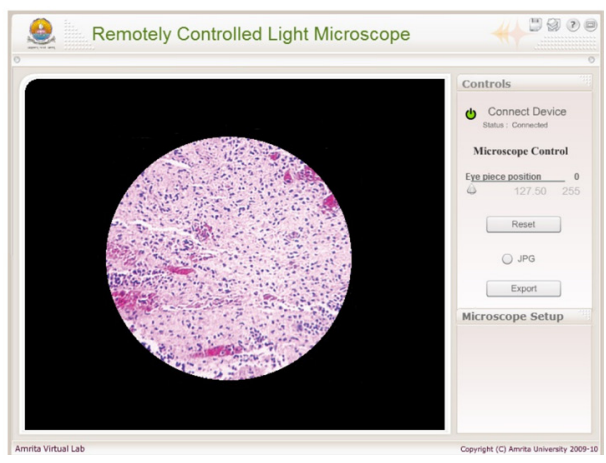

Figure 3.

A. Remote lab set up of light microscope B. Output in GUI
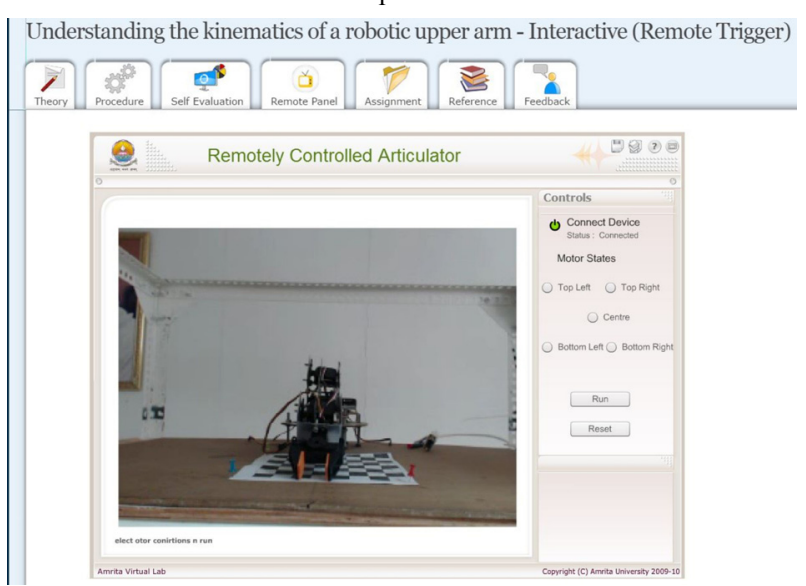

Figure 4. Remotely controlled articulator 
TABLE I.

LiST OF REMOTELY-CONTROLLED LABS IN BIOTECHNOLOGY AND BIOMEDICAL ENGINEERING RELATED TO THIS PAPER

\begin{tabular}{|c|c|}
\hline \multirow{2}{*}{ SI.No } & Neurophysiology Virtual Labs \\
\hline & Name of experiments \\
\hline 1 & Study of Synaptic Transmission \\
\hline 2 & Understanding the Passive Properties of a Simple Neuron \\
\hline 3 & Effects of Ion Channels in Membrane Biophysics \\
\hline 4 & Effect of Noise on Spiking Neurons \\
\hline \multicolumn{2}{|r|}{ Bio-inspired Robotics Virtual Labs } \\
\hline 1 & Controlling a servo motor in a bio-robotic environment \\
\hline 2 & Understanding the kinematics of a robotic upper arm \\
\hline 3 & $\begin{array}{l}\text { Understanding the kinematics of a robotic upper arm - } \\
\text { Interactive }\end{array}$ \\
\hline 4 & Light sensing process in a neural circuit \\
\hline 5 & $\begin{array}{l}\text { Mechanism behind the movement of a Walker robot with } \\
4 \text { neurons }\end{array}$ \\
\hline 6 & Interaction study with Neuronal Circuits \\
\hline 7 & Constructing a six core brain like circuit \\
\hline 8 & Pattern recognition in a hardware neural network \\
\hline \multicolumn{2}{|r|}{ Biophysics Virtual labs } \\
\hline 1 & Using a light microscope \\
\hline 2 & Observing an animal cell using a light microscope \\
\hline 3 & Study of RC Properties of Cell Membrane \\
\hline 4 & Study of Electrically excitable cells \\
\hline 5 & Bursting phenomenon in biology via RC models \\
\hline 6 & Micrometry \\
\hline 7 & $\begin{array}{l}\text { Multicompartmental modelling of biophysical behaviour } \\
\text { of neurons }\end{array}$ \\
\hline 8 & $\begin{array}{l}\text { Understanding Photosynthesis as a Biologically Closed } \\
\text { Process }\end{array}$ \\
\hline
\end{tabular}

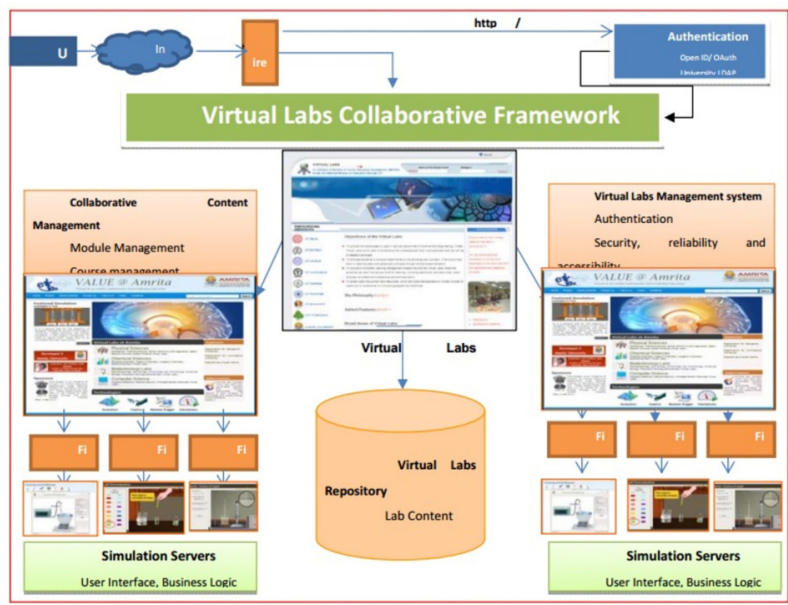

Figure 5. Architecture of virtual and remote labs

\section{METHODS}

\section{A. Remote labs usage case study amongst students}

As a part of this study, we introduced Neurophysiology virtual labs and Biophysics virtual labs as a course study material to 3 consecutive years of academic batches (2012, 2013 and 2014) of postgraduate students from the same University. Overall, 150 students participated in this study. Students were shown demonstrations to control experiments and equipment with the help of an interface window which can be viewed through browsers. The time given to complete one experiment was 2 hours in a week.
After completing each experiment (a total of 12 experiments, 4 from Neurophysiology and 8 from biophysics), students marked the feedback questions (Yes/No) on the feedback tab [30] and individual scores of each question were recorded. Usability of remote labs was analyzed based on the access data and statistics recorded in the virtual lab server. The questions for analysis are listed as Table II.

TABLE II.

ONLINE FEEDBACK QUESTIONS USED FOR ANALYSIS

\begin{tabular}{|c|l|}
\hline SI.No & \multicolumn{1}{c|}{ Feedback Questions } \\
\hline 1 & $\begin{array}{l}\text { The online performance of the experiment was satisfacto- } \\
\text { ry throughout the lab hours. }\end{array}$ \\
\hline 2 & $\begin{array}{l}\text { The control of remote experiments and equipment was } \\
\text { sufficient to understand the concepts. }\end{array}$ \\
\hline 3 & The results of the experiment were easily interpreted. \\
\hline 4 & $\begin{array}{l}\text { Remote labs are a complementary tool for practicing real } \\
\text { labs and equipment based studies. }\end{array}$ \\
\hline 5 & $\begin{array}{l}\text { I could run the remote experiments easily without inter- } \\
\text { pretations. (If No, specify the problems faced). }\end{array}$ \\
\hline
\end{tabular}

The semester examination scores of students evaluated with assignments from virtual neurophysiology labs were also noted. We excluded conducting examination for Biophysics since it was only an elective course for smaller set of students.

\section{B. Student-feedback based analysis on relative advantages of remote labs}

To estimate relative advantage of the use of remote labs questions on learning quality (LQ), ease of use (EU), Understandability (US), remembering concepts (RC) and overall advantage (OA) were used in the feedback survey [27]. Questionnaire included in the feedback survey were shown (see Table III)

TABLE III.

FEEDBACK Questions For Testing Relative AdVANTAges OF REMOTE LABS

\begin{tabular}{|c|c|}
\hline Sl.No & Feedback Questions \\
\hline 1 & $\begin{array}{l}\text { Usage of remote labs will improve the quality of my } \\
\text { studies (LQ). }\end{array}$ \\
\hline 2 & Remote labs will make it easier to do my studies (EU). \\
\hline 3 & $\begin{array}{l}\text { My interaction with remote labs is clear and understanda- } \\
\text { ble (US). }\end{array}$ \\
\hline 4 & Remote labs help me remember the concepts better (RC). \\
\hline 5 & $\begin{array}{l}\text { Overall I would find using remote labs to be advantageous } \\
\text { in my studies (OA). }\end{array}$ \\
\hline
\end{tabular}

The user rated their responses "yes", which indicated the users positive response and "no", which indicated the negative response.

\section{User behavior and trends in the usage of remote labs - Workshop based case study}

To understand diffusion of remote labs among various users including teachers and students, we conducted 4hour workshops for 500 students and 250 teachers from different engineering and Biotechnology institutes all over India. The main objective of the workshop was to provide a comprehensive overview of the role of remote labs in education and to train the participants with the remotely controlled lab experiments. After completing the lab exer- 
cises remotely, the participants were asked to evaluate a questionnaire-based feedback on the usage of remote labs. The feedback survey included questions (see Table IV) with rating on Likert-scale numerical values from 1 to 5 (1- Very poor, 2- Poor, 3- Average, 4- Good, 5- Excellent).

TABLE IV.

FEEDBACK QUESTIONS INCLUDED IN THE WORSHOP BASED CASE STUDY

\begin{tabular}{|c|l|}
\hline SI.No & \multicolumn{1}{|c|}{ Feedback Questions } \\
\hline 1 & How do you rate the online performance of the experiment? \\
\hline 2 & To what extent do you control the equipment interactions? \\
\hline 3 & Remote labs are helpful in science education. \\
\hline 4 & The results of the experiments could be easily interpreted. \\
\hline
\end{tabular}

Individual points scored for each question by the participants (teachers and students) were summed and the perceived role of remote laboratories was analyzed.

Additionally, post-workshop, in order to assess teacher's interest to include virtual lab and remote labs in their syllabus, we asked them an additional question regarding their expression to coordinate a nodal center at their school or universities. A nodal center is an institute directly advised by the project and used virtual labs as a part of their regular curriculum. By becoming a nodal center, the teachers and students also gained additional teaching and learning material and lab support. After 6 months we conducted a nodal center conference for the registered teacher coordinates of different universities and collected their feedback (both written and verbal feedback) to evaluate the role of virtual techniques (animation, simulation and remote equipment) in their curriculum.

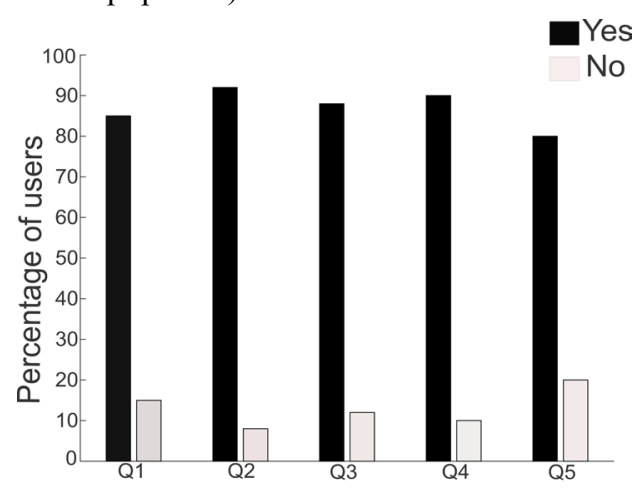

Feedback questions

Figure 6. Remote labs as supplementary education tool in universities

\section{RESULTS}

\section{A. Remote labs supplement laboratory training and practice in universities}

From participant feedback, $85 \%$ of them suggested that the online performance of the experiment was satisfactory throughout the lab hours. 92\% students supported the control of remote experiments and equipment was sufficient for them to understand the concepts. $88 \%$ students indicated that they could easily interpret results of the experiments. $90 \%$ of them supported remote labs as a complementary tool for practicing real labs and equipment based studies. $80 \%$ of the students indicated that they could run the remote experiments easily without any interpretations (Figure 6) while 20\% (\# 30) faced issues in using remote labs. Feedback analysis indicated student's choice of using remote labs as a supplementary tool in their learning (see Table V).

Feedback analysis showed correlation of learning issues with actual setup of remote laboratories. Analysis suggested adding solutions before deploying remote labs as massive online courses.

TABLE V.

LIST OF REMOTE LABS IN BIOTECHNOLOGY AND BIOMEDICAL ENGINEERING VIRTUAL LABS

\begin{tabular}{|c|l|c|}
\hline Sl.No & $\begin{array}{c}\text { Problems faced in using remote labs (as } \\
\text { per the feedback survey) }\end{array}$ & $\begin{array}{c}\text { Percentage of } \\
\text { students }\end{array}$ \\
\hline 1 & Scheduler or slot management system & 66.67 \\
\hline 2 & Delays in executing experiments & 60 \\
\hline 3 & Fluctuations in electricity & 33 \\
\hline 4 & Control instability of lab setup & 30 \\
\hline 5 & Increased buffer length for streaming video & 50 \\
\hline 6 & Internet issues & 26.67 \\
\hline
\end{tabular}

TABLE VI.

EXAMINATION SCORES OF STUDENTS USING REMOTE LABS As A LABORATORY MATERIAL

\begin{tabular}{|c|c|c|c|}
\hline \multirow{2}{*}{ Percentage of Marks } & \multicolumn{3}{|c|}{ Percentage of Students (year wise) } \\
\cline { 2 - 4 } & $\mathbf{2 0 1 2}$ & $\mathbf{2 0 1 3}$ & $\mathbf{2 0 1 4}$ \\
\hline$>90$ & 20 & 32 & 30 \\
\hline $80-90$ & 30 & 36 & 32 \\
\hline $70-80$ & 14 & 16 & 18 \\
\hline $60-70$ & 18 & 10 & 6 \\
\hline $50-60$ & 10 & 4 & 10 \\
\hline$<50$ & 8 & 2 & 4 \\
\hline
\end{tabular}

Results show that (Figure 6) remote labs were used as a laboratory material by postgraduate students of an Indian University. The examination scores of the students in 2012, 2013 and 2014 were shown (see Table VI). Results indicated that more than $90 \%$ of students scored above $50 \%$ marks in their examination aiding remote labs as an optional laboratory material and a source for conducting examinations.

\section{B. User behavior analysis - Remote labs as an online education material}

Data collected from the participants of workshops on remote labs were also used to determine the user behavior trends in using remote labs. $80 \%$ of students and $85 \%$ of teachers indicated the online performance of the experiments in remote labs as excellent for achieving the needs of the university education. $85 \%$ of students and $75 \%$ of teachers supported they could control the remote equipment from a distant place without the help of an instructor. $75 \%$ students and $80 \%$ teachers indicated Remote labs as a useful material in supporting science education. About 85 to $90 \%$ participants were able to analyze the results of the experiment easily (Figure 7). The findings support the usage of remote labs as complementary education tool for enhancing classroom performance. Feedback indicated materials provided by the educational platform were consistent with the objectives of the experiment and helped them to interpret the results in a better way. Poor rating ( 5 $\%-10 \%$ ) was correlated to some server issues faced by the participants during the workshop events. 


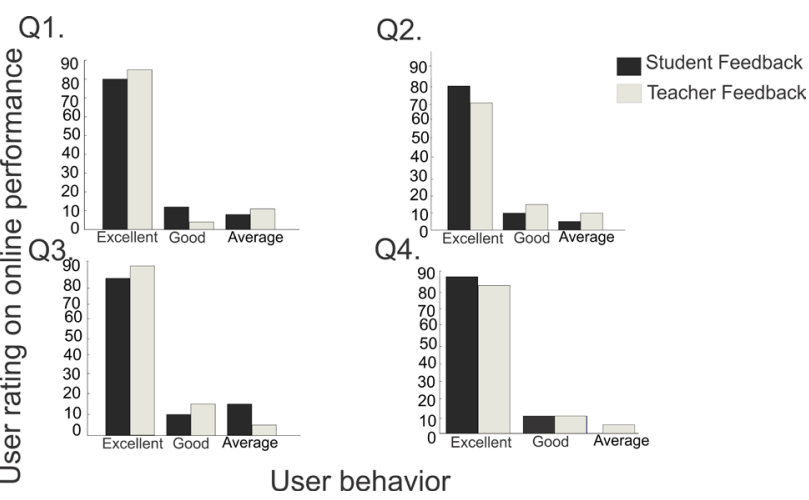

Figure 7. Trends in usage of remote labs by university teachers and students

The post-usage survey of virtual and remote labs indicated that most teachers were using these labs as both prelab and post-lab education material. Some of the nodal center coordinates commented (as is):" "In our college laboratory, students share lab equipment and perform the experiment by forming a group of 10 members. Most students may not get access to the lab setup. Introducing virtual and remote lab setup helped students practicing the experiment individually". "Interesting and valuable platform. Successful implementation of these online in all the colleges will definitely change the quality of graduating students". "Remote lab as a new venture in education stream helped students to practice the lab equipment without causing any damage. It is easy accessible tools that are used as both pre-lab and post lab materials by the students in our university".

\section{Remote labs as interactive textbooks to gain student attention in a laboratory environment}

Most users approved that remote labs helped them to improve their quality of learning (LQ). Also, participants supported that their interaction with remote labs was unambiguous and understandable (US). They also supported that remote labs helped them to remember both theoretical and practical concepts (RC) helping them augment their academic performance. It also allowed them to make their studies easier (EU) allowing users to experience laboratory feel beyond the walls of the classroom. Analysis of usability of remote labs amongst the student groups implicated a relative advantage of using remote labs in a classroom-based education (Figure 8).

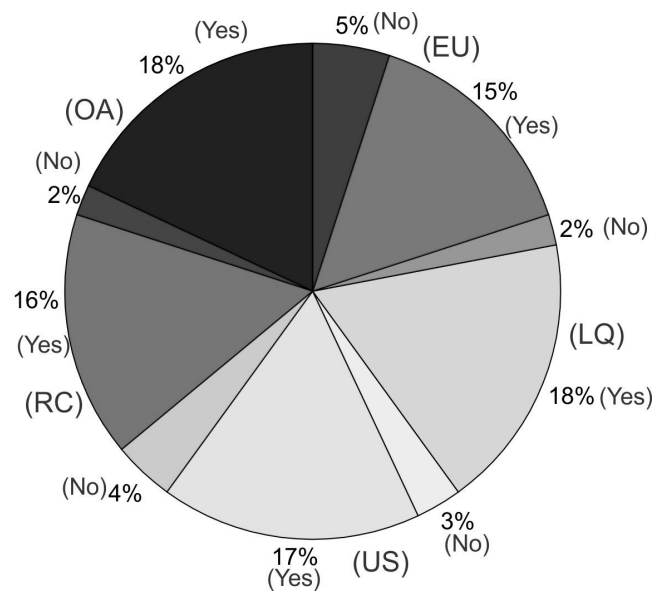

Figure 8. Relative Advantage (Usability) of remote labs in enhancing higher education.

\section{DISCUSSION AND CONCLUSION}

Remotely controlled laboratory equipment augmented student practice time on devices beyond scheduled classroom hours. Most users seemed comfortable with the usage of remote labs adding to the perceived usefulness of remote labs in teaching and learning. Similarly, the results from the feedback amongst students reports that remote labs could be applied as an effective learning material for conducting laboratory examinations. With relative advantage for remote lab users, current studies suggested the usage of online labs as a next generation interactive textbook by teachers and students for supporting their laboratory education. Users also correlated learning issues when internet or connectivity was poor and when devices failed. Additionally, the role of virtual labs in complementing education has basis on the usability of online tools, given $90 \%$ users reporting virtual labs as easy to use. It may be vital to understand the role of augmenting virtualization in the absence of actual device. To understand the potential role of remote labs in education needs behavioral analysis using electroencephalography, evaluation methods and surveys on individual and clustered classroom groups.

Using remote labs in blended environments allowed students to perceive some laboratory components as in traditional laboratory courses. Several issues need to be solved before deploying remote labs as massive online courses. We also noted that connectivity may affect user's perceived usefulness of remote labs. Usage case studies indicate remote labs could be introduced as a complementary educational tool to reinforce conceptual understanding, and for experiential learning. For India and developing countries, such platforms augment generic and specific discrepancies in laboratory resources and environments across institutions and in coping with the problem of under-equipped laboratories.

\section{ACKNOWLEDGMENT}

This project derives direction and ideas from the Chancellor of Amrita University, Sri Mata Amritanandamayi Devi.Authors would like to acknowledge the contributions of Hareesh Singanamala, Mithula Parangan, Chithra Asok, Rahul Sreekumar in development of remote labs.

\section{REFERENCES}

[1] L. Feisel and A. Rosa, "The Role of the Laboratory in Undergraduate Engineering Education," J. Eng. Educ., vol. 94, no. 1 , pp. 121-130, 2005. http://dx.doi.org/10.1002/j.21689830.2005.tb00833.x

[2] S. Mitra, R. Dangwal, and S. Chatterjee, "Acquisition of computing literacy on shared public computers: Children and the" hole in the wall,", Australas. J. ..., pp. 1-17, 2005.

[3] B. F, "Education in Rural India: Perspective from a North Indian Village," no. August, pp. 1-53, 2008.

[4] M. Casini, D. Prattichizzo, and A. Vicino, "E-LEARNING BY REMOTE LABORATORIES: A NEW TOOL FOR CONTROL EDUCATION Marco Casini, Domenico Prattichizzo, Antonio Vicino," 2000.

[5] J. Ma and J. V. Nickerson, "Hands-on, simulated, and remote laboratories," ACM Comput. Surv., vol. 38, no. 3, p. 7-es, Sep. 2006.

[6] M. Auer, a. Pester, D. Ursutiu, and C. Samoila, "Distributed virtual and remote labs in engineering," IEEE Int. Conf. Ind. Technol. 2003, pp. 1208-1213, 2003.

[7] A. Maiti and B. Tripathy, "Remote laboratories: Design of experiments and their web implementation," Educ. Technol. Soc., vol. 16, no. 3, pp. 220-233, 2013. 
[8] B. F. Woodfield, "Book review - Accessible elements: Teaching science online and at a distance," The International Review of Research in Open and Distributed Learning, vol. 11, no. 3. pp. $158-163,2010$

[9] C. A. Korey, "Teaching undergraduate neuroscience in the digital age.," J. Undergrad. Neurosci. Educ., vol. 8, no. 1, pp. A55-7, Jan. 2009.

[10] B. Nair, R. Krishnan, N. Nizar, R. Radhamani, K. Rajan, A. Yoosef, G. Sujatha, V. Radhamony, K. Achuthan, and S. Diwakar, "Role of ICT-enabled visualization-oriented virtual laboratories in Universities for enhancing biotechnology education - VALUE initiative: Case study and impacts," FormaMente, vol. 7, no. 1, pp. 209-229, 2012.

[11] Z. Nedic, J. Machotka, and A. Nafalski, "Remote laboratories versus virtual and real laboratories," in 33rd Annual Frontiers in Education, 2003. FIE 2003., 2003, vol. 1, pp. T3E_1-T3E_6.

[12] N. Sousa, G. R. Alves, and M. G. Gericota, "An Integrated Reusable Remote Laboratory to Complement Electronics Teaching," IEEE Trans. Learn. Technol., vol. 3, no. 3, pp. 265271, 2010. http://dx.doi.org/10.1109/TLT.2009.51

[13] K. K. S. Pandian, M. Rao, and S. Khandekar, "Remote-access real-time laboratory: process monitoring and control through the internet protocol," Int. J. Mech. Eng. Educ., vol. 36, no. 3, pp. 207-220, Jul. 2008. http://dx.doi.org/10.7227/IJMEE.36.3.4

[14] V. J. Harward, J. a. Del Alamo, S. R. Lerman, P. H. Bailey, J. Carpenter, K. DeLong, C. Felknor, J. Hardison, B. Harrison, I. Jabbour, P. D. Long, T. Mao, L. Naamani, J. Northridge, M. Schulz, D. Talavera, C. D. Varadharajan, S. Wang, K. Yehia, R. Zbib, and D. Zych, "The iLab shared architecture: A web services infrastructure to build communities of internet accessible laboratories," Proc. IEEE, vol. 96, no. 6, pp. 931-950, 2008. http://dx.doi.org/10.1109/JPROC.2008.921607

[15] E. Lindsay, D. Liu, S. Murray, and D. Lowe, "Remote laboratories in engineering education: Trends in students' perceptions," Proc. 2007 ..., no. MicroLogix 1200, pp. 1-6, 2007.

[16] T. Richter, Y. Tetour, and D. Boehringer, "Library of Labs - A European Project on the Dissemination of Remote Experiments and Virtual Laboratories," in 2011 IEEE International Symposium on Multimedia, 2011, pp. 543-548. http://dx.doi.org/10.1109/ISM. 2011.96

[17] S. Malani, G. N. S. Prasanna, J. A. del Alamo, J. L. Hardison, K. Moudgalya, and V. Chopella, "Issues Faced in a Remote Instrumentation Laboratory," in 2012 IEEE Fourth International Conference on Technology for Education, 2012, pp. 67-74. http://dx.doi.org/10.1109/T4E.2012.21

[18] M. P. Kazmierkowski, "Advances on Remote Laboratories and eLearning Experiences," in IEEE Industrial Electronics Magazine, no. June, 2008, pp. 45-46.

[19] A. Mittal, C. Gupta, and A. Gupta, "Addressing the Bandwidth Efficiency, Control, and Evaluation Issues in Software Remote Laboratory," IEEE Trans. Ind. Electron., vol. 55, no. 6, pp. 23262333, Jun. 2008. http://dx.doi.org/10.1109/TIE.2008.922582

[20] S. Ray, N. R. Koshy, S. Diwakar, B. Nair, and S. Srivastava, "Sakshat Labs: India's Virtual Proteomics Initiative," PLoS Biol., vol. 10, no. 7 , p. e1001353, Jul. 2012. http://dx.doi.org/10.1371/ journal.pbio. 1001353

[21] S. Diwakar*, K. Achuthan, P. Nedungadi, and B. Nair*, "Enhanced Facilitation of Biotechnology Education in Developing Nations via Virtual Labs: Analysis, Implementation and Casestudies," Int. J. Comput. Theory Eng., vol. 3, no. 1, pp. 1-8, 2011.

[22] R. Radhamani, H. Sasidharakurup, D. Kumar, N. Nizar, B. Nair, K. Achuthan, and S. Diwakar, "Explicit Interactions by Users Form a Critical Element in Virtual Labs Aiding Enhanced Education -- A Case Study from Biotechnology Virtual Labs," in 2014 IEEE Sixth International Conference on Technology for Education, 2014, pp. 110-115. http://dx.doi.org/10.1109/t4e. $\underline{2014.37}$

[23] C. Huang, "Changing learning with new interactive and mediarich instruction environments: virtual labs case study report.," Comput. Med. Imaging Graph., vol. 27, no. 2-3, pp. 157-64, Jan. 2003. http://dx.doi.org/10.1016/S0895-6111(02)00089-7

[24] D. Kumar, H. Singanamala, K. Achuthan, S. Srivastava, B. Nair, and S. Diwakar, "Implementing a Remote-Triggered Light Microscope," in Proceedings of the 2014 International
Conference on Interdisciplinary Advances in Applied Computing ICONIAAC '14, 2014, pp. 1-6. http://dx.doi.org/10.1145/2660859. 2660963

[25] S. Diwakar, K. Achuthan, and P. Nedungadi, "Biotechnology Virtual Labs - Integrating Wet-lab Techniques and Theoretical Learning for Enhanced Learning at Universities," in 2010 International Conference on Data Storage and Data Engineering, 2010, pp. 10-14. http://dx.doi.org/10.1109/DSDE.2010.22

[26] S. Diwakar, H. Parasuram, C. Medini, R. Raman, P. Nedungadi, E. Wiertelak, S. Srivastava, K. Achuthan, and B. Nair, "Complementing Neurophysiology Education for Developing Countries via Cost-Effective Virtual Labs: Case Studies and Classroom Scenarios.," J. Undergrad. Neurosci. Educ., vol. 12, no. 2, pp. A130-9, Jan. 2014.

[27] M. Cooper and J. M. M. Ferreira, "Remote Laboratories Extending Access to Science and Engineering Curricular," IEEE Trans. Learn. Technol., vol. 2, no. 4, pp. 342-353, Oct. 2009. http://dx.doi.org/10.1109/TLT.2009.43

[28] J. Freeman, A. Nagarajan, M. Parangan, D. Kumar, S. Diwakar, and K. Achuthan, "Remote triggered photovoltaic solar cell lab: Effective implementation strategies for Virtual Labs," in 2012 IEEE International Conference on Technology Enhanced Education (ICTEE), 2012, pp. 1-7. http://dx.doi.org/10.1109/ ICTEE.2012.6208653

[29] S. Xiong, "Web Single Sign-On System For WRL Company," Royal Institute of Technology (KTH), IT-University Stockholm, Sweden, 2005.

[30] R. Raman, P. Nedungadi, K. Achuthan, and S. Diwakar, "Integrating Collaboration and Accessibility for Deploying Virtual Labs using VLCAP," Int. Trans. J. Eng. Manag. Appl. Sci. Technol., vol. 2, no. 5, pp. 547-560, 2011.

\section{AUTHORS}

Shyam Diwakar is the Principal Investigator and lab Director of Computational Neuroscience Laboratory and an Assistant Professor at the School of Biotechnology. Amrita University, India. $\mathrm{He}$ is a co-investigator of VALUE (Virtual and Accessible Laboratories for Universalizing Education); a virtual labs initiative supported by Sakshat mission of MHRD, Government of India. (e-mail: shyam@amrita.edu, address: Amrita School of Biotechnology, Amrita Vishwa Vidyapeetham (Amrita University), Amritapuri, Clappana P.O., Kollam, 690 525, Kerala, India).

Dhanush Kumar is currently working as Development Engineer in VALUE Virtual labs at Amrita Vishwa Vidyapeetham University, India. (address: Amrita School of Biotechnology, Amrita Vishwa Vidyapeetham (Amrita University), Amritapuri, Clappana P.O., Kollam, 690 525, Kerala, India).

Rakhi Radhamani, Hemalatha Sasidharakurup, and Nijin Nizar, are currently working as Research Associate in VALUE Virtual labs at Amrita Vishwa Vidyapeetham University, India (address: Amrita School of Biotechnology, Amrita Vishwa Vidyapeetham (Amrita University), Amritapuri, Clappana P.O., Kollam, 690 525, Kerala, India).

Krishnashree Achuthan is Dean of PG programs at Amrita University. She is also the Principal Institute Coordinator, VALUE (Virtual and Accessible Laboratories for Universalizing Education); a virtual labs initiative supported by Sakshat mission of MHRD, Government of India. She is also the Director of Technology Business Incubator and the Center for Cyber-security, which has been recognized as a TIFAC center of excellence by Government of India (e-mail: krishna@amrita.edu, address: Amrita School of Engineering, Amrita Vishwa Vidyape- 
etham (Amrita University), Amritapuri, Clappana P.O., Kollam, 690 525, Kerala, India).

Prema Nedungadi is the director at Amrita Center for Research in Advanced Technologies for Education (CREATE), Amrita Vishwa Vidyapeetham University, India (e-mail: prema@amrita.edu, address: Amrita CREATE, Amrita Vishwa Vidyapeetham (Amrita University), Amritapuri, Clappana P.O., Kollam, 690 525, Kerala, India).

Raghu Raman is the Chairman for Amrita School of Business, Amrita Vishwa Vidyapeetham University, India. (e-mail: raghu@amrita.edu, address: Amrita School of Engineering, Amrita Vishwa Vidyapeetham (Amrita
University), Amritapuri, Clappana P.O., Kollam, 690 525, Kerala, India) .

Bipin Nair is the Professor and Dean of School of Biotechnology, Amrita University. He is also the Discipline wise National Coordinator for the development of Biotechnology Virtual Labs being developed under the MHRD-NMEICT program. (bipin@amrita.edu, address: Amrita School of Biotechnology, Amrita Vishwa Vidyapeetham (Amrita University), Amritapuri, Clappana P.O., Kollam, 690 525, Kerala, India).

This work is funded under the Sakshat project of National Mission on Education through ICT (Phase I and Phase II), Department of Higher Education, MHRD, Government of India.

Submitted 21 december 2015. Published as resubmitted by the authors 27 February 2016. 